\title{
A SÉ DE LISBOA NA FUNDAÇÃO DO REINO PORTUGUÊS ${ }^{1}$
}

\section{THE LISBON CATHEDRAL AT THE FOUNDATION OF THE PORTUGUESE KINGDOM}

Willian Funke $e^{2}$

Resumo: O texto que segue está integrado ao conjunto de resultados do primeiro momento da pesquisa sobre a Sé de Lisboa. O objetivo inicial era compreender qual a posição, o lugar, da Catedral no contexto de expansão portuguesa sobre territórios islâmicos na Península Ibérica e consolidação de Portugal enquanto unidade política autônoma. Este objetivo desdobrava-se em compreender os usos da Sé e as relações que se estabeleciam a partir dela, sejam da própria Sé com outras instituições ou de Portugal como um todo com outros organismos. Além destes, era importante também a análise da Sé enquanto construção, em seus aspectos materiais. No presente artigo apresento alguns pressupostos da pesquisa, faço uma breve descrição da Sé - incluindo-a no contexto de sua construção - e, por fim, exponho as relações lidas a partir da Catedral de Lisboa, encerrando o texto com conclusões que servem de indicativos para a sequência dos trabalhos.

Palavras-chave: Sé de Lisboa; Portugal Medieval, Românico, Reconquista.

Abstract: This text is a part of results from de first moment of the research about the Lisbon Cathedral. The first goal was to understand

\footnotetext{
${ }^{1}$ Este texto é fruto da pesquisa individual realizada pelo estudante como atividade do PET História UFPR. A pesquisa também deu origem a um banner apresentado no X Encontro Internacional de Estudos Medievais da ABREM, com o mesmo título deste artigo.

${ }^{2}$ Estudante do sétimo período do curso de História - Licenciatura e Bacharelado da Universidade Federal do Paraná. Bolsista do PET História UFPR e membro discente do NEMED. Orientado pela Professora Doutora Marcella Lopes Guimarães. E-mail para contato: wfunke@yahoo.com.br. Endereço para o currículo lattes: http://lattes.cnpq.br/7573330518137906.
} 
what the position, the place, of Cathedral in context of Portuguese expansion into Islamic lands in Península Ibérica and consolidation of Portugal as an independent unit. This goal unrolled on understanding the uses of the Cathedral and the relationships that were established from it, are the Cathedral itself with other institutions or Portugal as a whole with other agencies. In addition, it was also important to the analysis of the Cathedral while building on its material aspects. In this article I present some premises of research, make a short description of the Cathedral - including it in the context of its construction - and finally expose the relationships read from the Cathedral of Lisbon, ending the text with conclusions that serve as indicative for the following work.

Keywords: Lisbon Cathedral; Medieval Portugal; Romanesque; Reconquista.

Por trás dos grandes vestígios sensíveis da paisagem, [os artefatos ou as máquinas,] por trás dos escritos aparentemente mais insípidos e as instituições aparentemente mais desligadas daqueles que as criaram, são os homens que a história quer capturar. Quem não conseguir isso será apenas, no máximo, um serviçal da erudição. Já o bom historiador se parece com o ogro da lenda. Onde fareja carne humana, sabe que ali está a sua caça. (BLOCH, 2001: 54)

\section{Introdução}

Se todos os vestígios humanos podem comunicar mais do que simplesmente são (um templo, uma casa...), as construções não seriam apenas edifícios. Elas nos informam a respeito de que tipos de materiais estavam disponíveis em dados locais no período de sua realização; a organização espacial nos informa sobre relações sociais; a complexidade da edificação nos testemunha os meios disponíveis para o trabalho. Mas para além do que uma construção é e do que lemos em uma observação mais apurada, existe ainda o que a obra representa, significa. E essa representação/significação é historicamente construída pelas pessoas 
que vivenciam e dão vida a este espaço. Assim, a intenção deste estudo é ler o lugar que a Sé ocupou no contexto em que Portugal se formava e consolidava.

No século XII Portugal encontrava-se em processo de expansão para o sul, sobre territórios muçulmanos do ocidente da Península Ibérica - de maneira descontínua, com avanços e retrocessos - ao mesmo tempo em que tentava se firmar como unidade política autônoma de Leão. Nesse período ocorriam as cruzadas, com o objetivo manifesto de conquistar a Terra Santa para os cristãos. Uma das comitivas organizadas para a Segunda Cruzada partiu da Inglaterra e ingressaria no Mediterrâneo em direção ao Oriente, mas numa parada para abastecimento em Portugal - em junho de 1147 - foi requisitada pelo rei Afonso Henriques para ajudar na tentativa de conquistar Lisboa. Apesar de questionarem a validade da ajuda aos portugueses, frente ao objetivo primeiro de participar da Cruzada do Oriente e que vantagens esse auxílio lhes traria, os cruzados decidiram por ficar e combater ao lado do monarca lusitano. O Cerco a Lisboa foi iniciado em 01 de julho de $1147 .^{3}$

Falamos que Afonso Henriques era rei de Portugal quando pediu ajuda aos cruzados. Ele o era, mas precisamos problematizar esta informação para entender as dificuldades de Portugal em ser reconhecido e

\footnotetext{
${ }^{3}$ Sobre a conquista de Lisboa aos muçulmanos e todo o movimento prévio tomamos como base a carta do cruzado R., texto escrito durante a viagem dos cruzados até Lisboa e o cerco a essa cidade, a qual foi consultada através da edição de Aires A. Nascimento que a intitula A Conquista de Lisboa aos Mouros - Relato de um cruzado, modo pelo qual preferi referir o documento (A CONQUISTA DE LISBOA..., 2001). Essa edição também contém a Notícia da Fundação do Mosteiro de São Vicente de Lisboa.
} 
se manter autônomo. Afonso Henriques disputou a sucessão do condado Portucalense com sua mãe, Dona Teresa, filha de Afonso VI de Leão e Castela. Após derrotar militarmente a mãe, prendeu-a. O primeiro monarca português teve diversas vitórias no campo de batalha, sendo aclamado rei por seus soldados após uma dessas vitórias, no Campo de Ourique. A aclamação, porém, não significou pronto reconhecimento de seu reinado e da independência de Portugal pelos outros reinos e pelo Papado (MATTOSO, 2011: 61-79; 157-178). Ocorreram diversos embates, bélicos e diplomáticos, para que Portugal se mantivesse independente, o que será importante para entendermos alguns dos resultados apresentados adiante.

Voltando ao cerco de Lisboa, Afonso Henriques mandou construir duas igrejas para que se pudessem sepultar com as dignidades cristãs os soldados mortos no período em que cercavam a cidade. Estes campos santos deram origem à Igreja de Santa Maria dos Mártires e ao Mosteiro de São Vicente de Fora. Os habitantes de Lisboa resistiram bravamente, mas os cristãos acabaram por vencer e conseguir que os resistentes capitulassem no fim de outubro de 1147. Foi assinado um acordo de rendição, pelo qual os derrotados entregariam todos os seus bens a um grupo de cruzados e sua integridade seria respeitada. Quando do saque, no entanto, o que se presenciou foram cenas de violência e desrespeito ao que havia sido acordado (A CONQUISTA DE LISBOA..., 2001: 107$109 ; 131-141)$. 


\section{A materialidade de Sé}

Depois de passado o ímpeto inicial da entrada na cidade o Bispado da Sé de Lisboa foi conferido pelo rei a D. Gilberto, prelado que acompanhava a expedição cruzada, de nação inglesa. D. Gilberto prestou juramento de lealdade a D. João Peculiar, arcebispo de Braga (A CONQUISTA DE LISBOA..., 2001: 141-143). Iniciaram-se as obras de construção da Sé, as quais não se podem datar com exatidão, mas devem ter começado pouco depois de 1147. A construção do corpo da igreja ocorreu entre a segunda metade do século XII e princípios do XIII, e do claustro posteriormente. Desde então vem sofrendo diversas intervenções, seja por motivo do desgaste natural, da intenção de mudá-la, ou pelos danos causados pelos terremotos ${ }^{4}$ (FIGUEREDO, 2008). Além do claustro, foram anexados à primitiva edificação da Sé o Camarim do Patriarca, a capela de São Bartolomeu e a Sacristia. A capela-mór que vemos hoje e respectivo deambulatório também são posteriores a construção do corpo da igreja.

\footnotetext{
${ }^{4}$ Lisboa sofreu vários abalos sísmicos ao longo da história. São destacados por FIGUEREDO (2008) cinco que ocorreram nó século XIV - 1327, 1334, 1337, 1344,1356 - e o grande terremoto de 1755 que destruiu grande parte da cidade e derrubou parte da Catedral.
} 


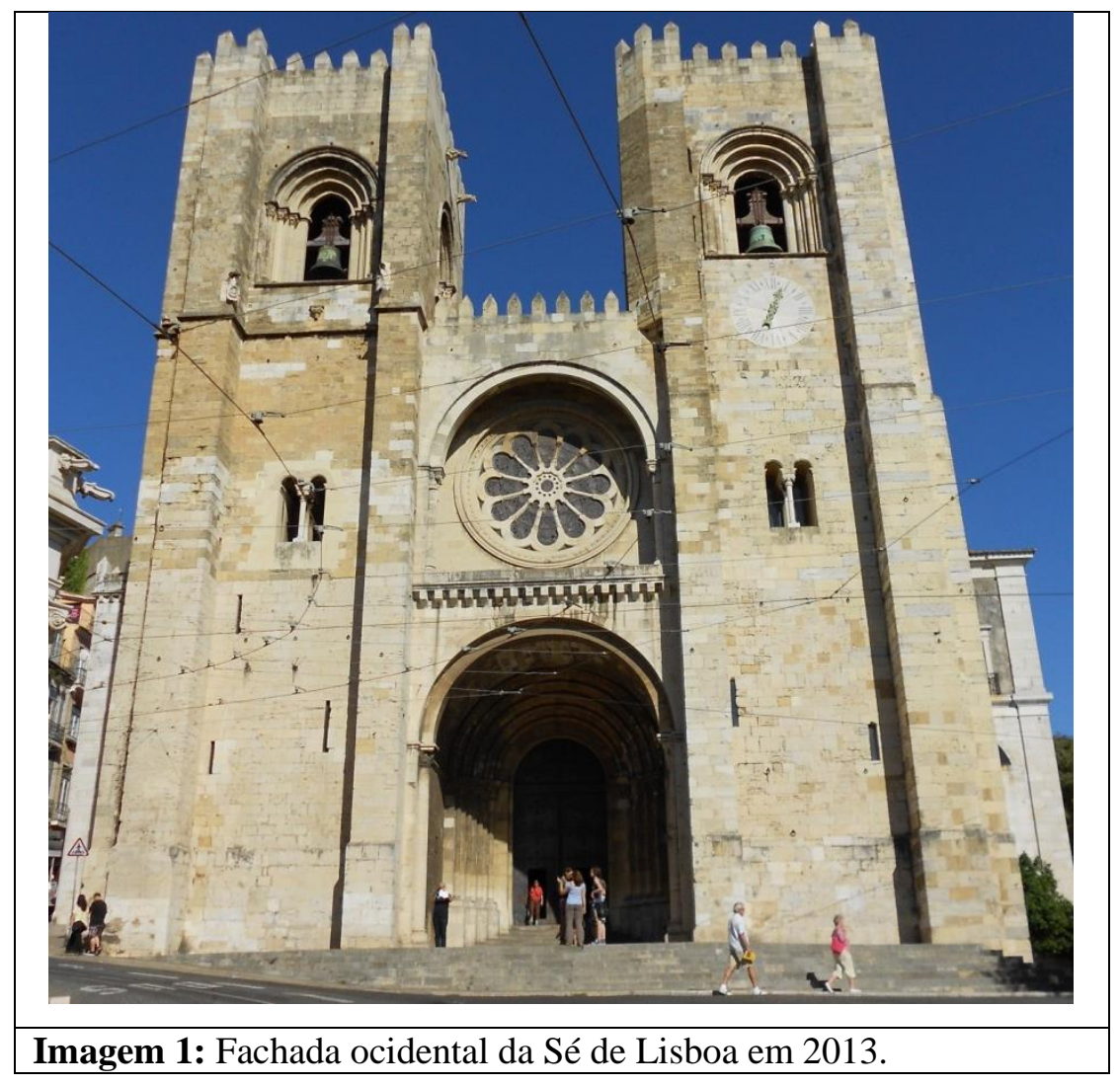

A Catedral de Lisboa é a única obra do estilo Românico, e também a única do período de Afonso Henriques que hoje sobrevive na cidade, ainda que profundamente modificada. O Românico é um estilo que podemos definir como compacto, que passa a imagem de consistência e robustez. Não seria de estranhar que um desavisado confundisse a Igreja com uma fortaleza ou um castelo, o que estaria dentro dos propósitos de demarcação de posse pretendidos pela instalação de um templo cristão numa cidade recém-conquistada. 
Sobressaem-se os estilos Românico no corpo da igreja e Gótico em seus deambulatório e claustro, dando testemunho da época em que foram construídos, ambos repletos de influências da arte Mudéjar (VILLAMARIZ, 2004). Havendo ainda diversos contributos de períodos posteriores. $^{5}$

O corpo da igreja é composto por três naves, a central com abóbada de berço em cantaria e as laterais com abóbadas de aresta. É constituído por seis tramos e sobre o primeiro avança o coro alto. Por sobre as naves laterais, mais baixas que a central, corre uma galeria (trifório) com abertura em arcaria, sendo quatro aberturas em cada tramo. Os arcos torais da abóbada da nave central se prolongam até os pilares polistilos.

${ }^{5}$ Seria ainda necessário falar dos processos de restauro pelos quais passou a Catedral. No momento deixamos a indicação da leitura do texto "Os restauros da Catedral de Lisboa à luz da mentalidade dos tempos” (NETO, 1999). 


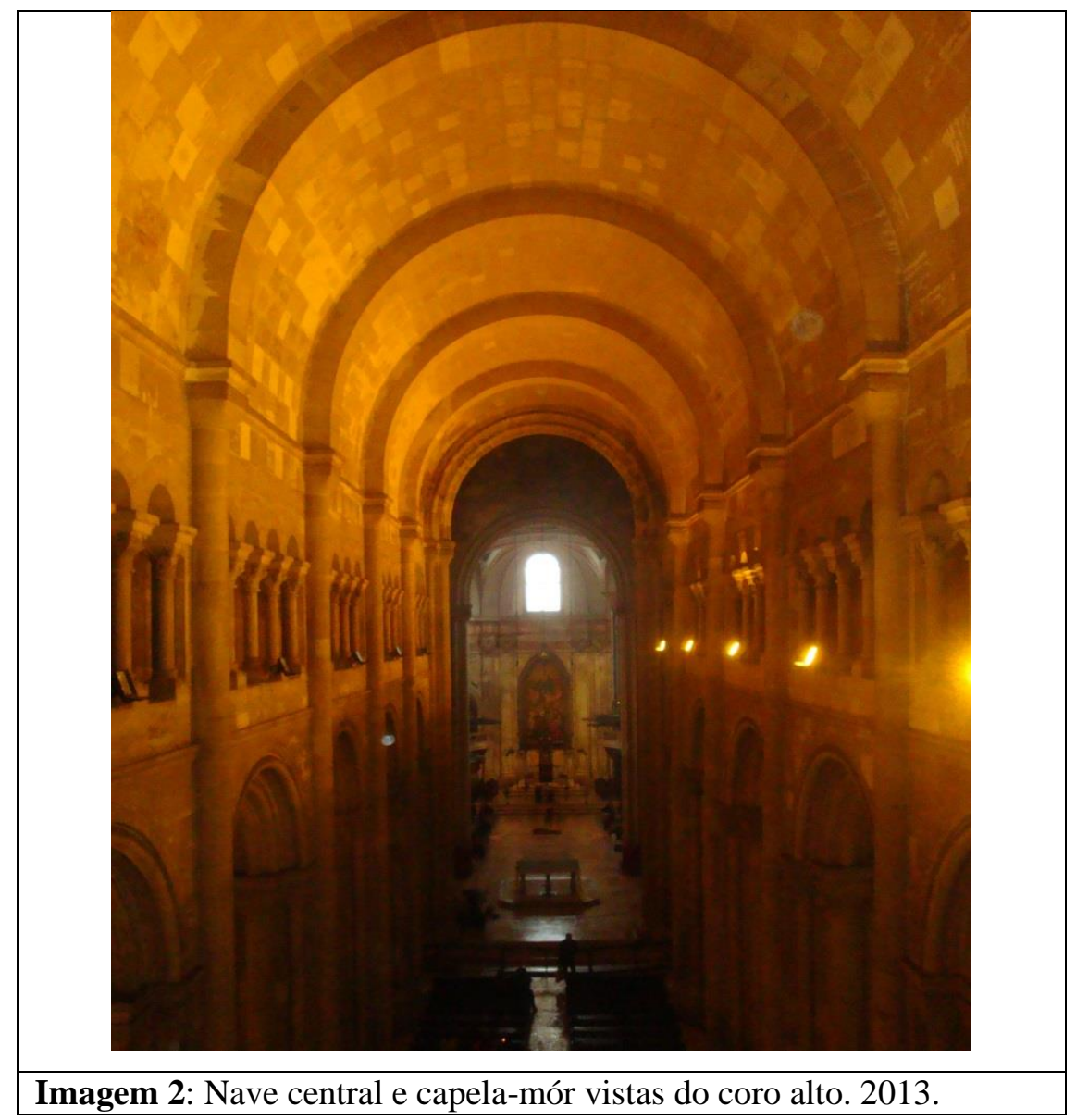

O Gótico pode predominar no claustro, tanto pelo período de edificação, como por a cidade já estar consolidada enquanto cristã. Este contexto permitiu que se pensasse, antes do estilo, na própria construção deste espaço, que como nos diz Catarina Villamariz, não era um elemento obrigatório nas catedrais (VILLAMARIZ, 2004: 154). O Claustro é composto por três galerias irregulares, devido ao desnível do terreno. 
Posicionado atrás da capela-mór, intersecciona a planta do corpo da igreja no deambulatório.

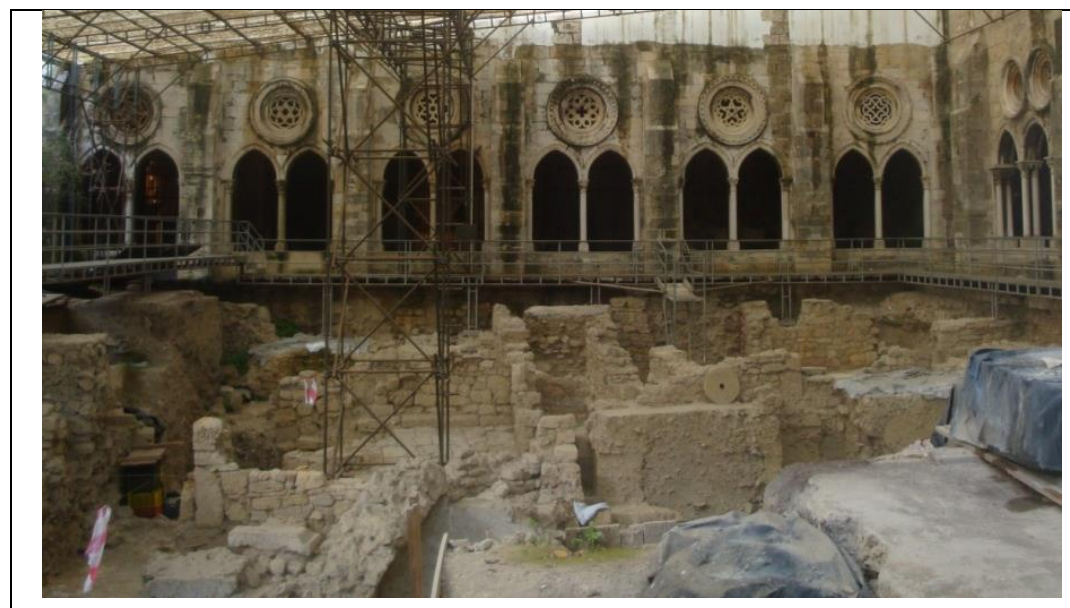

Imagem 3. Galeria Norte e escavações do claustro da Sé de Lisboa vistas a partir da Galeria Sul. 2013.

Os elementos Mudéjares denunciam o fluxo e influência exercida pelos muçulmanos nos territórios por eles perdidos. Diferente do que ocorre na análise de Andrea Piccini para o espaço florentino (PICCINI, 2009), no qual as influências arquitetônicas devem-se a relações comerciais, na Península Ibérica houve a coabitação, ou seja, os elementos Mudéjares não eram exógenos, pelo contrário. Por mais que os portugueses tenham avançado sobre território islâmico e o conquistado, não seria possível apagar todos os vestígios da presença anterior, por mais que se tenha tentado. É significativo que, além dos elementos decorativos presentes na construção cristã - a exemplo dos óculos observados por sobre os arcos na imagem 3 - a Sé esteja provavelmente edificada 
sobre as bases da Mesquita que ocupava o mesmo espaço quando a cidade ainda era muçulmana. ${ }^{6}$

\section{Usos da Sé}

No tocante aos empregos da Sé destacamos: o cerimonial, na realização das missas, em especial a primeira celebração depois de tomada a cidade, realizada - provavelmente - ainda na mesquita; a escola catedralícia, na qual Santo Antonio iniciou seus estudos (SOUZA, 2001); e o uso como última morada, para sepultamentos (VILLAMARIZ, 2004).

A primeira missa rezada quando da efetivação da conquista era um marco, tão importante quanto se ter hasteado as armas do rei e a cruz nas muralhas da cidade, uma vez que a guerra além do objetivo de conquista de terras tinha a motivação religiosa de expansão da fé cristã. Chama-nos a atenção o fato de a missa em questão poder ter sido celebrada ainda na Mesquita. Além da necessidade de um espaço para a realização do culto, isso pode representar a passagem do domínio da cidade das mãos islâmicas às cristãs, sendo necessário considerar que esse já era o principal espaço sagrado da cidade.

A escola presente na Sé de Lisboa, apesar de comum em outras igrejas, no caso lisboeta pode nos indicar uma tentativa de ampliação do raio de ação do bispo na sociedade ainda em formação. Os diversos sepultamentos que ocorriam na Sé traziam rendas para a igreja, uma vez que ocorriam doações nas fundações das capelas que receberiam os seus

${ }^{6}$ Segundo Villamariz (2004), a mesquita que havia no local foi derrubada para dar lugar a Catedral, mas isso não é consenso. Ainda segundo a autora, a decoração da arcaria (imagem 3) seria arabizante. 
fundadores e familiares, e também para a celebração de missas dos que estavam ali sepultados. E o fato de as pessoas quererem ser ali enterradas e pagarem por isso nos leva a pensar que a Sé era um espaço privilegiado de culto e devoção. Além de ser a principal igreja de Lisboa, guardava as relíquias de São Vicente, o que comentaremos mais a frente.

\section{Relações a partir da Sé de Lisboa}

Outros dados que chamam a atenção são as relações apreendidas a partir da Sé de Lisboa. A própria Sé tinha uma relação conflituosa com o mosteiro de São Vicente de Fora, o que não era uma particularidade lisboeta, tendo em vista que a hierarquia monacal escapava ao poder episcopal, ligando-se à autoridade do Papa por outros caminhos que não através dos bispos. O mosteiro de São Vicente estava protegido pelo rei, devido às divisões que haviam sido feitas entre os portugueses e os estrangeiros que tomaram parte no cerco. As igrejas construídas para o sepultamento dos cristãos mortos nas batalhas do cerco de Lisboa (Santa Maria dos Mártires e São Vicente) ficaram uma ligada ao Bispo da cidade e outra ao rei (CRÔNICA DE PORTUGAL DE 1419, 1998: 53).

Além da questão hierárquica há a disputa pela maior quantidade de fiéis, que considero ser o principal motivo para a querela envolvendo as relíquias de São Vicente, achadas vinte e seis anos depois de tomada de Lisboa e levadas para a cidade. O que entendo é que deveriam esperar o julgamento do rei para que fossem depositadas na Sé ou no mosteiro, mas a Sé acabou por se apossar dos vestígios do mártir sem que essa 
situação fosse posteriormente revertida (CRÔNICA DE PORTUGAL DE 1419, 1998: 65-66). Ainda em relação a essa disputa, a Notícia da Fundação do Mosteiro de São Vicente de Lisboa, aponta como motivo para a escolha da igreja de Santa Maria dos Mártires pela Sé de Lisboa o fato de receber mais fiéis, representando mais entradas para os cofres do bispado. ${ }^{7}$ Com isso, depreende-se que a rivalidade entre a Sé e o Mosteiro se baseia na busca de maior fluxo de pessoas e consequentemente mais doações.

Pode-se também ler relações de Portugal tendo a Sé como ponto de partida. Para conquistar Lisboa, o rei Afonso Henriques contou com ajuda de estrangeiros, cruzados que se encaminhavam para o oriente. Para pagar pelo auxílio ofereceu parte do espólio da cidade a ser conquistada. Entendo que este é um dos motivos pelos quais Afonso Henriques indicou o inglês Gilberto para bispo da cidade, além da riqueza material, a indicação faria parte da recompensa.

Outras relações que apreende-se a partir da Sé são as de Portugal com o reino de Leão e Castela e com o papado de Roma. As duas estão no bojo da luta travada pelo jovem reino, personalizada em seu rei, pela autonomia política. Afonso Henriques declarou-se rei após vitória nos campos de Ourique e o fez contra os interesses de Leão e Castela, do qual Portugal era condado. A mãe do monarca português era filha de Afonso VI, imperador do reino vizinho, por isso e por outros motivos a

\footnotetext{
${ }^{7}$ Teria sido dada ao Bispo a opção de ter sob sua a autoridade a Igreja de Santa Maria dos Mártires ou o Mosteiro de São vicente de Fora. Cf. "Notícia da Fundação de S. Vicente de Lisboa" (A CONQUISTA DE LISBOA ..., 2001: 178201).
} 
independência de Portugal era extremamente frágil e qualquer sinal de autonomia muito importante nesse cenário de incertezas.

Voltando à sagração de Gilberto como bispo, ele jurou lealdade, em nome da Sé de Lisboa, ao arcebispo de Braga. Entretanto, antes da conquista muçulmana Lisboa estava ligada a Mérida, esta última sucedida em direitos episcopais por Compostela. Esta, por sua vez, concorria com Braga e Toledo pela primazia espiritual na Península Ibérica. Assim a ligação de Lisboa ao arcebispado do território português é um dos fatores deste cenário. Ao fazer com que o bispado olissiponense ficasse subordinado ao Arcebispo Braga, Afonso Henriques mantém o controle eclesiástico da cidade recém conquistada dentro de seus domínios, diferente do que poderia ocorrer se a subordinação ocorresse segundo o que se esperaria num contexto em que Portugal continuasse ligado a Leão e Castela. Nesse caso - em princípio - o bispado de Lisboa deveria ser sufragâneo de Compostela. O Papa ter confirmado a ligação da Sé recém restaurada é um indicativo de que a relação com Portugal está mais amena que em outros momentos, como quando Afonso Henriques contrariou ordens papais e prendeu um enviado de Roma (CRÔNICA DE PORTUGAL DE 1419, 1998: 27-34).

As diferenças com Roma parecem já estar bem acalmadas quando da conquista de Lisboa. O rei ainda não havia conseguido a confirmação de seu título pelo Sumo Pontífice, mas - desde 1143 - era vassalo da Santa Sé (MATTOSO, 1997: 64-66). A escolha e sagração do Bispo Gilberto de forma expressa - sem sequer se cogitar esperar a opinião do Papa, que confirmou a decisão de Afonso Henriques (CRÔNICA DE 
PORTUGAL 1419, 1998) - demonstra que o rei português conseguira autoridade sobre as questões religiosas dentro de sue reino, o que dependia de alguma anuência do papado.

\section{Conclusões}

Conclui-se que este templo religioso teve uma importância além da espiritual, tanto para Lisboa como para Portugal. Com a interpretação proposta não tornamos a Sé o principal elemento das relações externas do jovem reino, ou o foco de todas as atenções da cidade recém conquistada em todos os momentos. Apenas posicinamo-la como mais um dos diversos pontos de conflito, ou concórdia entre o reino de Afonso Henriques e o vizinho Leão e Castela ou o Papado; além de conferir um espaço para a Igreja no contexto da cidade, onde, porém, concorria no mínimo com o Mosteiro de São Vicente. Não podemos esquecer as influências Mudéjares presentes na Sé, as quais nos mostram que, mesmo após a invasão da cidade, os muçulmanos não saíram completamente dela, além de alguns habitantes, deixaram também elementos de sua cultura, a ver a língua em que escrevemos este trabalho.

Assim o lugar ocupado pela Sé de Lisboa no Portugal em formação é o de um espaço no qual ocorriam disputas e através do qual Afonso Henriques buscava legitimar seu poder. Também um local em que são lidas heranças que os muçulmanos deixaram na cidade. Ainda que importante, este lugar não é exclusivo, e a teia de relações existente entre as igrejas da Península Ibérica mostra o quão variados e instáveis poderiam ser essas posições. Questão a respeito da qual se pretende 
discutir de modo mais focado em um momento posterior da pesquisa. Esse lugar não foi dado quando da edificação da Sé, foi construído com as atitudes que os aqueles com ela relacionados tomaram ao longo do tempo.

\section{Bibliografia}

A Conquista de Lisboa aos Mouros - Relato de um Cruzado. NASCIMENTO, Aires A, (ed., trad. e notas). Lisboa: Vega, 2001.

Crónica de Portugal de 1419. CALADO, Adelino de Almeida (ed.). Aveiro, Universidade de Aveiro, 1998.

BLOCH, Marc. Apologia da história, ou, O ofício de historiador. André Telles (Trad.). Rio de Janeiro: Jorge Zahar Ed., 2001.

BRANDÃO, Francisco, Terceira parte da Monarchia Lusytana: que contem a historia de Portugal, desde o Conde Dom Henrique, até todo o Reynado d'El rey Dom Afonso Henriques. Lisboa: Impressão Craesbeeckiana, 1690.

CUNHA, Rodrigo da. História Ecclesiastica da Igreja de Lisboa. Vida, e acçoens de seus prelados, \& varoes eminentes em santidade, que nella florecerão. Lisboa: Por Manoel da Sylva, 1642.

FERNANDES, Fátima Regina. "Cruzadas na Idade Média”. In: MAGNOLI, Demétrio. História das Guerras. São Paulo: Contexto, 2009. pp. 98-129.

FIGUEIREDO, Paula. Catedral de Lisboa / Sé de Lisboa / Igreja Paroquial da Sé Patriarcal / Igreja de Santa Maria Maior. Sistema de informação para o Património Arquitectónico, 2008. Disponível em: http://www.monumentos.pt/Site/APP_PagesUser /SIPA.aspx?id=2196. Acesso em: 31 de outubro de 2013.

MARQUES, A. H. de Oliveira. Breve história de Portugal. Lisboa: Presença, 1998. 
MOREIRA, Filipe Alves. Afonso Henriques e a primeira crónica portuguesa. Porto: Estratégias Criativas, 2008.

MATTOSO, José. História de Portugal, Vol. II, A Monarquia Feudal (1096-1480). Lisboa: Editorial Estampa, 1997.

2011.

. D.Afonso Henriques. 2 ${ }^{\mathrm{a}}$ Edição. Lisboa: Temas e Debates,

NETO, Maria João Baptista. Os restauros da Catedral de Lisboa à luz da mentalidade dos tempos. In BARROCA, Mario Jorge (coord.). Carlos Alberto Ferreira de Almeida in memorian. Porto: Faculdade de Letras da Universidade do Porto, 199. Volume 2. pp. 131-141.

PICCINI, Andrea. Arquitetura: do Oriente Médio ao Ocidente, a transferência de elementos arquitetônicos através do Mediterrâneo até Florença. São Paulo: Annablume, 2009.

SOUZA, José Antonio de Camargo R. O Pensamento Social de Santo Antônio. Porto Alegre: EDIPUCRS, 2001.

VILLAMARIZ, Catarina. "A Sé de Lisboa e a Arquitectura Claustral". In Krus, Luís; Miranda, Maria Adelaide; ALARCÃO, Miguel. A Nova Lisboa Medieval. Lisboa: Edições Colibri, 2004, pp. 153-164.

As imagens usadas no artigo compõem o acervo do autor.

Recebido em: 23/05/2014 Aceito em: 17/08/2014 